\title{
The Philosophy of Memory Today and Tomorrow: Editors' Introduction
}

\author{
Kourken Michaelian, Dorothea Debus, and \\ Denis Perrin
}

\section{The Philosophy of Memory Today}

As Bernecker and Michaelian point out in their introduction to the recent Routledge Handbook of Philosophy of Memory (2017), it is hardly surprising, given that memory is one of our most fundamental cognitive capacities and the source of an enormous fraction of our knowledge, that philosophical interest in memory dates back to the dawn of philosophy and has remained strong throughout the history of the discipline. What is surprising is the fact that the philosophy of memory has only recently emerged as a recognized field of research. Whatever the explanation for the delayed emergence of the field, it now most definitely has emerged, with the publication of the Handbook being only the most obvious sign of this development. Other signs include the rapid proliferation of workshops, conferences, and special issues on the topic of memory and the establishment, at the Issues in Philosophy of Memory conference held in Cologne in 2017, of the PHilosophy Of Memory Organization (phomo.org). There is, in short, a lot going on in the philosophy of memory today, and, whereas the entries for the Handbook were compiled so as to provide a systematic overview of historical and contemporary philosophical research on memory, the present volume, New Directions in the Philosophy of Memory, offers a snapshot of some of the most active and dynamic areas of current research.

\section{Overview of the Book}

The book has seventeen chapters (not including this introduction). The chapters are grouped into six parts, of which we here provide brief overviews.

\subsection{Part I: Challenges and Alternatives to the Causal Theory of Memory}

Though the causal theory, which was given its classical formulation by Martin and Deutscher (1966), has for long been the dominant philosophical theory of remembering (see, e.g., Bernecker, 2010; Cheng \& Werning, 2016), it has in recent years come under increasing pressure, and the 


\section{Kourken Michaelian et al.}

three contributions to Part I consider challenges and alternatives to the theory. According to the classical causal theory, the occurrence of genuine remembering presupposes the existence of a certain sort of causal connection between the subject's apparent memory and his earlier experience of the remembered event, namely, a causal connection sustained by a memory trace originating in that experience. As Michaelian and Robins demonstrate in their chapter, increasing recognition among philosophers of the thoroughly reconstructive character of remembering (e.g., Robins, forthcoming; Salvaggio, forthcoming) has led to the formulation not only of versions of the causal theory that attempt to do without memory traces but also of postcausal theories that reject the necessity of causal connection for genuine remembering outright. Inspired both by Sutton's (1998) philosophical work on distributed memory storage and attributionalist approaches to memory in psychology (Whittlesea, 1997), Perrin develops a theory of the former sort. According to his procedural causal theory, the causal connection characteristic of remembering obtains not between the retrieved memory and the earlier experience but rather between the reconstructive process that produces the memory and the constructive process that produced the experience. Though quite far from the theory defended by Martin and Deutscher, Perrin's theory is recognizably a causal theory. The functionalist theory developed by Fernández, in contrast, joins postcausal theories such as the simulation theory (Michaelian, 2016; cf. De Brigard, 2014) in advocating the outright rejection of the necessity of causal connection for remembering. Applying general functionalist approaches developed in philosophy of mind, Fernández argues that a memory state should be understood as a state of a sort that tends to be caused by the corresponding earlier experience but that it need not in fact be caused by that experience.

\subsection{Part II: Activity and Passivity in Remembering}

Both Perrin's argument for the procedural causal theory and Fernández's argument for the functionalist theory are informed by a conception of remembering as an active, reconstructive process. The three chapters that make up Part II share this conception, but rather than proposing general theories of reconstructive remembering, they focus specifically on its active dimension. Building on recent work on feeling-based metacognition (see, e.g., Proust, 2013; Dokic, 2014), Arango-Muñoz and Bermúdez argue that, far from being a matter of the passive storage and retrieval of information, remembering is a matter of reconstructing the past and that this reconstruction qualifies, in virtue of the role played in it by metacognitive feelings, as a form of full-fledged mental action. Like Arango-Muñoz and Bermúdez, Hutto and Peeters abandon the passive, storage-and-retrieval picture of remembering for a picture of remembering as the active reconstruction of the past. Building on a range of empirical research, including research on episodic memory as a form of mental time 
travel (Perrin \& Michaelian, 2017), they argue that radical enactivism (e.g., Hutto \& Myin, 2013, 2017) grounds a view of remembering, including experientially rich forms of episodic remembering, that dispenses entirely with the notion of stored content. There are potential links here both with the procedural causal theory defended by Perrin in his chapter, which likewise rejects the claim that remembering involves stored content, and with the relationalist account of memory defended elsewhere by Debus (2008), which rejects the view that retrieved memories have representational content. Debus' contribution to this volume may nevertheless be at odds with those of Hutto and Peeters and of Arango-Muñoz and Bermúdez, as it stresses that episodic or recollective memories have characteristic features of both activity and passivity. Adopting an epistemological perspective, Debus argues that memory is able to serve as a source and ground of knowledge because, when the subject remembers, the past impinges on him as a passive recipient. There may be less incompatibility with more reconstructive views here than one might initially think, however, as Debus also argues that the relevant type of passivity is compatible with at least some active intervention by the subject, such as that involved in switching from field to observer perspective (see McCarroll, forthcoming).

\subsection{Part III: The Affective Dimension of Memory}

Like a majority of the contributors to Part II, Gerrans understands memory as a form of mental time travel into the past, performed by the same neural systems responsible for mental time travel into the future. Whereas the contributions to Part II are concerned with the active dimension of remembering, understood as past-oriented mental time travel, Gerrans' contribution to Part III is concerned with another specific dimension of pastand future-oriented mental time travel, namely, its affective dimension. Mental time travel, he argues, in line with Goldie's (2012) narrative account and with accounts stressing the sense of ownership involved in memory (Fernández, forthcoming), can be understood as involving empathy for one's past or future selves. Focusing on the case of painful memories, he argues that, when one remembers, one can in a very literal sense share feelings with one's past self. One does this not, he claims, by simulating one's past experience in full, including one's past feeling of pain, but rather by simulating the feeling of being the person undergoing the pain. Arcangeli and Dokic are similarly concerned with the affective dimension of remembering, understood as past-oriented mental time travel. On one view of the relationship between memory and emotion, a memory can be about a past emotion. On another view, a memory can cause a present emotion. But on neither view can a memory itself have an emotional component. Arcangeli and Dokic, drawing, like Gerrans, on Goldie's account, argue for a novel view of the relationship between memory and emotion, suggesting that we must acknowledge, in addition to the perspective of the remembered 


\section{Kourken Michaelian et al.}

subject and the perspective of the remembering subject, the perspective of the narrator of the remembered event and that doing so enables us to acknowledge the possibility of memories with a genuinely emotional component, the idea being that genuinely affective memories occur as the narrator's emotional perspective directly influences the remembering subject's emotional perspective.

\subsection{Part IV: Memory in Groups}

The affective dimension of remembering is also at issue in Sutton's chapter, but whereas the contributions to Part III largely bracket the social dimension of remembering, Sutton seeks to bring these two dimensions together in a treatment of memory at the group level. Picking up on recent approaches to remembering as a collective process (Michaelian \& Sutton, 2017) and recent arguments for the possibility of distributed affectivity (Krueger \& Szanto, 2016), he argues that both remembering and feeling are sometimes socially shared, rather than internal or strictly individual, activities. In line with his previous argument for a complementarity-based approach to extended cognition (Sutton, 2010), however, he maintains that complementary relations between subjects in different affective states are often more important for the occurrence of collective remembering than is convergence among individuals in the same affective state. De Brigard's chapter likewise concerns the social or collective dimension of remembering, but whereas Sutton's focus is on affect, De Brigard's focus is on the abilities necessary for participation in joint reminiscing. He draws on earlier suggestions by Hoerl and McCormack (2004) and Campbell (2002) to explore the abilities on which this form of collective remembering depends, identifying three such abilities. Mental ostension consists in inward attention to a specific component of a memorial content. Deferred mental ostension is a matter of indirect attention through deference to a present mental content. Finally, concerted deferred mental ostension is the ability to guide someone else's attention inwardly toward the relevant aspect of the mental content.

\subsection{Part V: Memory Failure: Concepts and Ethical Implications}

Many of the chapters in the preceding parts of the book seek to understand how memory works when it does work; the chapters in Part V, in contrast, seek to understand how memory works when it fails. Frise's chapter takes up a topic that has so far been neglected in the philosophy of memory despite its obvious importance to the field, that of the nature of forgetting. Reviewing a range of discussions of forgetting in the philosophical and psychological literatures on memory, Frise considers and rejects the theories of the nature of forgetting implicit in these discussions on the ground that they fail two tests: they do not accommodate the existence of the feeling of forgetting (see Arango-Muñoz, 2013), and they do not accommodate 
the fact that some failures of prospective memory (see Szpunar, Spreng, \& Schacter, 2016) qualify as instances of forgetting. He therefore introduces a new theory, the LEarning, Access failure, Dispositional (LEAD) theory, and argues that it passes these tests. Bernecker's chapter is likewise concerned with forgetting, focusing not on its nature but rather on its ethics. Many have claimed that one cannot be held responsible for forgetting because it is not under one's control. Some (e.g., Matheson, 2017) have argued that forgetting is sometimes under one's control and that, when it is, one can be held responsible for it. Bernecker concurs but goes further, arguing that one can also sometimes be held responsible for forgetting even when it is not under one's control. Craver and Rosenbaum's chapter likewise has an ethical focus, but they are concerned with the ethical implications of a much more dramatic sort of memory failure, that manifested in cases of episodic amnesia. Writing from the point of view of researchers working with amnesic subjects, they interrogate the ability of such subjects to give meaningful consent to participate in experiments. While it might be thought that episodic amnesiacs are trapped in a "permanent present tense" (Corkin, 2013), they discuss evidence that amnesiacs are likely to have the capacities necessary for meaningful consent (e.g., Craver et al., 2014) and argue that a subject need not be able to recall the moment of consent in order for his consent to endure.

\subsection{Part VI: The Content and Phenomenology of Episodic and Semantic Memory}

The chapters making up the final part of the book are all concerned, in one way or another, with the content and phenomenology of episodic and semantic memory. Rowlands, in his chapter, sets out the idea, developed in his own recent work (Rowlands, 2017) and in that of others (Fernández, 2008), that the content of a retrieved episodic memory must be understood as referring not only to the remembered episode but also to the location of the remembered episode in the subject's personal past, suggesting that the latter aspect of episodic memory content can be described using the Fregean notion of a mode of presentation. He argues further that this implies that the content of an episodic memory is not independent of the act of remembering and that this entails that remembering is reconstructive in character. Soteriou similarly suggests that episodic remembering involves not only a representation of a past episode but also a representation of a temporal perspective on that episode. In opposition to recent arguments that have sought to undermine the distinction between remembering the past and imagining it (Michaelian, 2016), he argues that the distinction is underwritten by the different ways in which the temporal location of the represented event is determined: by the actual temporal location of the past event, in the case of remembering, and by the subject's intentions, in the case of imagining (cf. Hoerl, 2014). Whereas Soteriou is concerned with 


\section{Kourken Michaelian et al.}

the distinction between episodic memory and episodic imagination, Hoerl, in his chapter, is concerned with the distinction between episodic memory and semantic memory. The question of the distinguishing mark of episodic memory_of the nature of episodicity (Perrin \& Rousset, 2014)—is familiar, but Hoerl defends a new answer to the question, arguing that, while both episodic memory and semantic memory display an epistemic asymmetry between past and future, they do so in different ways, with episodic memory providing the subject with knowledge not only of past events but also of what it was like to experience them. Teroni, finally, is concerned with semantic rather than episodic memory, suggesting that, while the attitude of semantic remembering can be explained in terms of the feeling of familiarity, the feeling of familiarity does not itself justify semantic memory belief. Instead, he argues, it is the subject's past reasons for the belief, rather than the associated feeling of familiarity, that justifies a current semantic memory belief.

\section{The Philosophy of Memory Tomorrow}

Our intention, in putting this book together, was for it to provide a snapshot of current research directions in the philosophy of memory. What, then, does the snapshot reveal? Our overview of the book's contents suggests four key observations.

\subsection{Methodological Consensus}

First, there is now a stable consensus on the relevance of empirical research in psychology and other disciplines to the resolution of philosophical debates about memory. There remain, to be sure, differences of degree between those philosophers of memory who proceed in a more a priori manner and those who rely more heavily on empirical research. But virtually every chapter in the book is informed to some extent by empirical research, suggesting that the difference between relevant underlying methodological assumptions is much less stark than it was only a few years ago.

\subsection{Substantive Consensus}

Second, there is now a stable consensus on the active, reconstructive character of remembering. Whereas philosophers of memory until recently treated this as something to be defended (or attacked) by means of argument, the claim that memory has a reconstructive character now most often serves as a starting point for further argument. The psychology of memory is univocal in its endorsement of a reconstructive view, and this substantive consensus is no doubt in part a product of the methodological consensus noted previously. The consensus is on display throughout the book, but see especially the chapters in Part II. 


\subsection{New Questions About Memory}

Third, as consensus emerges on certain basic features of memory, philosophers of memory are asking new questions. These include more finegrained questions about previously neglected aspects of individual memory, such as the role of affect discussed in Part III. They include questions about previously neglected mnemic phenomena such as the sorts of memory failure discussed in Part V. And they include questions about remembering beyond the individual level, such as the forms of group memory discussed in Part IV.

\subsection{Back to Basics}

Finally, even as they ask new questions, philosophers of memory are displaying a new willingness to tackle afresh what is perhaps the most basic question of the philosophy of memory, that of the nature of remembering as such, by proposing radically new theories of remembering. As the contributions to Part I demonstrate, increasing methodological reliance on empirical results has suggested new ways of understanding the nature of remembering; these challenge the long-dominant causal theory without reverting to older epistemic or empiricist theories of memory. Along the same lines, the contributions to Part VI illustrate continuing attempts to solve the difficult puzzles posed by the relationship between episodic memory and episodic imagination and that between episodic memory and semantic memory.

Overall, this combination of methodological consensus and consensus on the broad contours of the phenomenon under investigation, on the one hand, with, on the other hand, active debate over specific features of the phenomenon and rival general theoretical characterizations of it suggests a field in good health. The state of the philosophy of memory today thus suggests a bright tomorrow for the field.

Acknowledgments: The initial idea for this book emerged through conversation among the editors at a conference in Grenoble in 2015. Many of the chapters were presented in preliminary form at two subsequent meetings, Memory and Subjectivity, held in Grenoble in mid-2016 and funded by a grant to Denis Perrin from the Institut Universitaire de France, and New Directions in the Philosophy of Memory, held in Dunedin in late 2016 and funded by a grant to Kourken Michaelian from the University of Otago. In addition to the funders, the editors wish to thank the contributors, all of whom delivered excellent chapters on time despite having to respect a tight deadline, as well as those colleagues (some themselves contributors and some not) who served as reviewers for the chapters.

\section{References}

Arango-Muñoz, S. (2013). Scaffolded memory and metacognitive feelings. Review of Philosophy and Psychology, 4(1), 135-152. 


\section{Kourken Michaelian et al.}

Bernecker, S. (2010). Memory: A philosophical study. Oxford: Oxford University Press.

Bernecker, S., \& Michaelian, K. (Eds.). (2017). The Routledge handbook of philosophy of memory. London: Routledge.

Campbell, J. (2002). Consciousness and reference. Oxford: Oxford University Press.

Cheng, S., \& Werning, M. (2016). What is episodic memory if it is a natural kind? Synthese, 193(5), 1345-1385.

Corkin, S. (2013). Permanent present tense: The unforgettable life of the amnesic patient, HM. New York: Basic Books.

Craver, C. F., Kwan, D., Steindam, D., \& Rosenbaum, R. S. (2014). Individuals with episodic amnesia are not stuck in time. Neuropsychologia, 57, 191-195.

De Brigard, F. (2014). Is memory for remembering? Recollection as a form of episodic hypothetical thinking. Synthese, 191(2), 155-185.

Debus, D. (2008). Experiencing the past: A relational account of recollective memory. dialectica, 62(4), 405-432.

Dokic, J. (2014). Feeling the past: A two-tiered account of episodic memory. Review of Philosophy and Psychology, 5(3), 413-426.

Fernández, J. (2008). Memory and time. Philosophical Studies, 141(3), 333-356.

Fernández, J. (Forthcoming). The ownership of memories. In M. García-Carpintero \& M. Guillot (Eds.), The sense of mineness. Oxford: Oxford University Press.

Goldie, P. (2012). The mess inside: Narrative, emotion, and the mind. Oxford: Oxford University Press.

Hoerl, C. (2014). Remembering events and remembering looks. Review of Philosophy and Psychology, 5(3), 351-372.

Hoerl, C., \& McCormack, T. (2004). Joint reminiscing as joint attention to the past. In N. Eilan, C. Hoerl, T. McCormack, \& J. Roessler (Eds.), Joint attention: Communication and other minds (pp, 260-286). Oxford: Oxford University Press.

Hutto, D. D., \& Myin, E. (2013). Radicalizing enactivism: Basic minds without content. Cambridge, MA: MIT Press.

Hutto, D. D., \& Myin, E. (2017). Evolving enactivism: Basic minds meet content. Cambridge, MA: MIT Press.

Krueger, J., \& Szanto, T. (2016). Extended emotions. Philosophy Compass, 11(12), 863-878.

Martin, C. B., \& Deutscher, M. (1966). Remembering. The Philosophical Review, 75(2), 161-196.

Matheson, D. (2017). An obligation to forget. In S. Bernecker \& K. Michaelian (Eds.), The Routledge handbook of philosophy of memory (pp. 364-372). London: Routledge.

McCarroll, C. (Forthcoming). Remembering from the outside: Personal memory and the perspectival mind. Oxford: Oxford University Press.

Michaelian, K. (2016). Mental time travel: Episodic memory and our knowledge of the personal past. Cambridge, MA: MIT Press.

Michaelian, K., \& Sutton, J. (2017). Collective memory. In M. Jankovic \& K. Ludwig (Eds.), The Routledge handbook of collective intentionality (pp. 140151). London: Routledge.

Perrin, D., \& Michaelian, K. (2017). Memory as mental time travel. In S. Bernecker \& K. Michaelian (Eds.), The Routledge handbook of philosophy of memory (pp. 228-239). London: Routledge. 
Perrin, D., \& Rousset, S. (2014). The episodicity of memory. Review of Philosophy and Psychology, 5(3), 291-312.

Proust, J. (2013). The philosophy of metacognition: Mental agency and selfawareness. Oxford: Oxford University Press.

Robins, S. K. (Forthcoming). Confabulation and constructive memory. Synthese.

Rowlands, M. (2017). Memory and the self: Phenomenology, science, and autobiography. Oxford: Oxford University Press.

Salvaggio, M. (Forthcoming). The justification of reconstructive and reproductive memory beliefs. Philosophical Studies.

Sutton, J. (1998). Philosophy and memory traces: Descartes to connectionism. Cambridge: Cambridge University Press.

Sutton, J. (2010). Exograms and interdisciplinarity: History, the extended mind, and the civilizing process. In R. Menary (Ed.), The extended mind (pp. 189-225). Cambridge, MA: MIT Press.

Szpunar, K. K., Spreng, R. N., \& Schacter, D. L. (2016). Toward a taxonomy of future thinking. In K. Michaelian, S. B. Klein, \& K. K. Szpunar (Eds.), Seeing the future: Theoretical perspectives on future-oriented mental time travel (pp. 21-35). Oxford: Oxford University Press.

Whittlesea, B. (1997). Production, evaluation, and preservation of experiences: Constructive processing in remembering and performance tasks. In D. L. Medin (Ed.), The psychology of learning and motivation: Advances in research and theory (Vol. 37, pp. 211-264). Cambridge, MA: Academic Press.

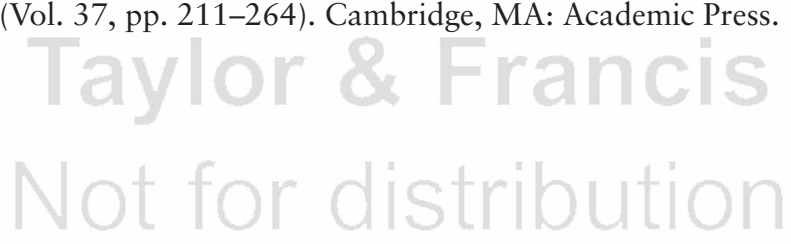


